\title{
PEMENUHAN KEBUTUHAN DASAR IBU HAMIL MELALUI "PEPES" (PENYULUHAN, PEMERIKSAAN DAN SENAM)
}

\section{COMPLIANCE OF BASIC NEEDS OF PREGNANT WOMEN THROUGH "PEPES" (COUNSELING, EXAMINATION AND PREGNANT EXERCISE)}

\author{
Wahyu Ersila ${ }^{1}$, Nina Zuhana ${ }^{2}$, Suparni $^{3}$ \\ ${ }^{1}$ Prodi Sarjana Fisioterapi, Universitas Muhammadiyah Pekajangan Pekalongan \\ ${ }^{2,3}$ Prodi DIII Kebidanan, Universitas Muhammadiyah Pekajangan Pekalongan \\ ersila.chila88@gmail.com
}

\begin{abstract}
ABSTRAK
Pendahuluan: Kehamilan merupakan bagian dari daur siklus seorang wanita dimana proses dari kehamilan akan menyebabkan wanita terjadi beberapa perubahan dalam dirinya. Perubahan tersebut meliouti fisik, mental dan sosial. Kebutuhan Dasar Ibu hamil secara fisik perlu dipenuhi agar ibu dalam menjalani kehamilannya terjaga kesehatannya. Kebutuhan tersebut meliputi oksigenasi, nutrisi, personal hiegine, pakaian, eliminasi, seksual, mobilisasi/body mekanik, istirahat/tidur. Kebutuhan dasar ibu hamil sangat mempengaruhi kesehatan ibu maupun janin selama masa kehamilan. Tidak terpenuhinya kebutuhan dasar ibu hamil, akan berdampak pada kesehatan ibu selama kehamilan dan juga secara langsung mempengaruhi proses persalinan kelak.

Tujuan:Mmeningkatkan pengetahuan ibu hamil mengenai kebutuhan dasar selama kehamilan

Metode :Ceramah tanya jawab, konseling pemeriksaan status gizi dan demonstrasi senam hamil.

Hasil :pengabdian masyarakat yang dilaksanakan selama 6 bulandai bulan Maret-Agustus 2019 menujukkan peningkatan pengetahuan ibu hamil dari 30 ibu hamil dengan pengetahuan baik $30 \%$ meningkat menjadi $63,3 \%$. Hasil uji marginal Homogeneity Test diperoleh nilai p 0,001 $(<0,05)$ hal ini berarti terdapat pengaruh sebelum dan setelah diberikan pendidikan kesehatan terhadap pengetahuan ibu mengenai kebutuhan dasar pada ibu hamil. Diskusi: Kegiatan Pengabdian Masyarakat ini terbukti mampu mengubah pengetahuan ibu hamil menjadi lebih baik, diharapkan mampu merubah sikap dan perilaku ibu hamil agar dapat terpenuhi kebutuhan dasar selama kehamilan, sehingga derajat kesehatan ibu dapat meningkat.
\end{abstract}

Kata Kunci : Kebutuhan dasar ibu hamil, penyuluhan, pemeriksaan, senam hamil

\begin{abstract}
Introduction: Pregnancy is a part of a woman's cycle where the process of pregnancy will cause a woman to make some changes in herself. These changes include physical, mental and social. Basic Needs Pregnant women physically need to be fulfilled so that mothers in carrying out their pregnancy are in good health. These needs include oxygenation, nutrition, personal hiegine, clothing, elimination, sexual, mobilization / mechanical body, rest / sleep. The basic needs of pregnant women greatly affect the health of both mother and fetus during pregnancy. Not meeting the basic needs of pregnant women, will have an impact on maternal health during pregnancy and also directly affect the labor process later.
\end{abstract}

Objective: Increase the knowledge of pregnant women about basic needs during pregnancy

Methods: Question and answer lecture, nutritional status check counseling and pregnancy exercise demonstration.

Results: community service carried out for 6 months in March-August 2019 showed an increase in knowledge of pregnant women from 30 pregnant women with good knowledge $30 \%$ increased to $63.3 \%$. Marginal Homogeneity Test results obtained p value of $0.001(<0.05)$ this means that there is an influence before and after health education is given to the mother's knowledge of basic needs in pregnant women.

Discussion: This Community Service activity is proven to be able to change the knowledge of pregnant women for the better, is expected to be able to change the attitudes and behavior of pregnant women in order to meet basic needs during pregnancy, so that the degree of maternal health can improve.

Keywords: Basic needs of pregnant women, counseling, examinations, pregnancy exercises 


\section{PENDAHULUAN}

Kehamilan merupakan suatu anugrah yang diberikan oleh tuhan kepada seorang wanita. Proses kehamilan seperti mata rantai yang saling berhubungan diantarannya mulai dari proses ovulasi, konsepsi, pertumbuhan zigot, nidasi (implantasi) pada uters pembentukan plasenta dan tumbuh kembang hasil konsepsi sampai dengan masa aterm (Manuaba, 2012).

Kehamilan terbagi menjadi 3 trimester yaitu trimeter pertama terjadi ketika usia kehamilan 1-3 bulan, trimester kedua saat kehamilan berusia 4-6 bulan, dan trimester ketiga saat usia kehamilan berusia 7-9 bulan (Pudiastuti, 2012). Ketika seorang menjalani proses kehamilan, akan terjadi perubahanperubahan pada diri wanita hamil tersebut. Perubahan itu meliputi fisik, mental dan sosial. Kebutuhan secara fisik perlu dipenuhi agar ibu menjalani kehamilannya dengan nyaman tanpa ada rasa khawatir, terutama bagi ibu yang pertama kali hamil. Kebutuhan dasar kaitannya dengan kebutuhan fisik diantaranya oksigenasi, nutrisi, personal, hiegienitas, pakaian, eliminasi, seksual, mobilisasi/body mekanik, dan istirahat/tidur. Kebutuhan dasar selama kehamilan sangat mempengaruhi kesehatan ibu maupun bayi dalam kandungannya. Tidak terpenuhi kebutuhan dasar selama kehamilan, akan berdampak pada kesehatan ibu dan bayi dan secara langsung akan mempengaruhi proses persalinannya kelak (Kuswanti, 2014).

Pengetahuan seorang ibu hamil akan sangat mempengaruhi pada keputusan dan perilakunya. Ibu hamil yang memiliki pengetahuan yang baik tentang pemenuhan kebutuhan dasar kehamilan, maka ia akan memiliki kesadaran dan memiliki sikap yang baik dalam menjalani kehamilannya. Purwaningrum (2017) dalam penelitiannya memperoleh hasil bahwa pengetahuan ibu mengenai kebutuhan nutrisi dalam kategori cukup. Hal ini perlu adanya pemberian informasi mengenai pemenuhan kebutuhan dasar pada ibu hamil yang didalam berisi bukan hanya mengenai gizi namun kebutuhan lain yang penting ibu hamil untuk mengetahuinya.

Hasil penelitian Goni, (2012) terdapat hubungan yang signifikan antara pengetahuan dan sikap ibu hamil degan status gizi selama hamil sehingga disarankan dalam penelitian tersebut harus banyak penyuluhan dan informasi pada ibu hamil untuk pengetahuan pemenuhan status gizi kehamilan. Hasil penelitian Khairi (2013) menyampaikan bahwa pengambilan keputusan, baik oleh suami atau diri sendiri yang gagal memenuhi kebutuhan nutrisi dipengaruhi oleh beberapa factor. Hasil penelitian menyarankan agar petugas kesehatan meningkatkan edukasi secara lebih intensif terkait nutrisi dan anemia dalam kehamilan, melibatkan partisipasi suamidan keluarga dalam edukasi dengan tetap memperhatikan aspek sosial budaya.

Tujuan pengabdian masyarakat ini adalah untuk meningkatkan pengetahuan, meningkatkan kesehatan ibu melalui pemeriksaan status gizi dan meningkatkan kebugaran ibu melalui senam hamil.

\section{METODE}

Kegiatan pengabdian masyarakat ini dilaksanakan di desa Tangkil Kulon Kecamatan Kedungwuni. Pelaksanaannya selama 6 bulan yaitu Maret-Agustus 2019 kegiatan mulai dari proses perencanaan, pelaksanaan dan evaluasi. Jumlah ibu hamil pada kegiatan ini adalah 30 ibu hamil. Yang dibatu oleh 1 bidan desa dan 7 orang kader.

Metode yang digunakan pada pengabdian masyarakat ini adalah:

a. Ceramah dan Tanya jawab: metode ini digunakan saat memberikan penyuluhan kebutuhan dasar pada ibu hamil. Sebelum melakukan penyuluhan, tim pelaksana memberikan kuesioner untuk mengukur pengetahuan ibu sebelum terpapar dengan materi (pretest). Penyuluhan ini dilakukan sebanyak $2 \mathrm{x}$ pertemuan dikarenakan materi yang banyak sehingga tidak memungkinkan bila disampaian satu kali pertemuan. Setelah selesai pemberian materi, tim pelaksana kembali membagikan kuesioner untuk mengevaluasi seberapa dalam materi yang telah disampaikan diterima oleh ibu hamil (prosttest).

b. Pemeriksaan : metode ini dilakukan untuk mengetahui status gizi pada ibu hamil. Pemeriksaan yang dilakukan antara lain; BB, TB, LILA, Hemoglobin, dan Gula 
Darah Sewaktu (GDS). Tujuan dari pemeriksaan ini adalah untuk mendeteksi resiko tinggi pada ibu hamil diantaranya deteksi anemia kehamilan, Kekurangan Energi Kronis, dan deteksi Diabetes mellitus selama kehamilan.

c. Demonstrasi : metode demontrasi dilakukan saat senam hamil dan praktik postur tubuh yang baik pada ibu hamil/ body mekanik ibu hamil. Ketika sesi senam hamil, instruktur menggunakan media LCD sehingga ibu hamil dapat melihat gerakan dengan detail meski posisinya ada pada bagian belakang. Selain itu tim pelaksana langsung menempatkan diri menyebar untuk mendampingi ibu hamil sehingga jika ada gerakan ibu hamil yang belum tepat langsung dapat di sesuaikan dengan gerakan yang benar.

\section{HASIL DAN PEMBAHASAN}

\section{HASIL}

Pelaksanaan pengabdian masyarakat ini dilaksanakan sebanyak $4 \mathrm{x}$ pertemuan, dengan rincian $2 \mathrm{x}$ penyuluhan, 1 xpemeriksaan dan $1 \mathrm{x}$ senam dan body mekanik. Kegiatan penyuluhan kebutuhan dasar pada ibu hamil memiliki tujuan untuk meningkatkan pengetahuan pada ibu hamil. Hasil pengetahuan ibu hamil disajikan pada tabel berikut ini.

Tabel 1. Distribusi Frekuensi pengetahuan ibu hamil sebelum dan setelah dilakukan penyuuhan

\begin{tabular}{ccccc}
\hline & \multicolumn{4}{c}{ Pengetahuan } \\
& Sebelum & $\%$ & Setelah & $\%$ \\
\hline Kurang & 5 & 16,7 & 0 & 0 \\
Cukup & 16 & 53,3 & 11 & 36,7 \\
Baik & 9 & 30 & 19 & 63,3 \\
\hline Total & 30 & 100 & 30 & 100
\end{tabular}

Berdasarkan tabel diatas dapat diketahui bahwa pengetahuan ibu hamil sebelum diberikan penyuluhan pada kategori cukup $16(53,3 \%)$, namun setelah dilakukan penyuluhan diperoleh hasil pengetahuan meningkat baik menjadi 19 $(63,3 \%)$.
Tabel 1.2. Analisis perbedaan pengetahuan sebelum dan setelah penyuluhan menggunakan uji marginal Homogeneity Test

\begin{tabular}{|c|c|c|c|c|}
\hline \multirow{2}{*}{$\begin{array}{l}\text { Pengetahuan } \\
\text { Sebelum }\end{array}$} & \multicolumn{2}{|c|}{$\begin{array}{c}\text { Pengetahuan } \\
\text { Setelah }\end{array}$} & \multirow{2}{*}{ Total } & \multirow{2}{*}{$\begin{array}{c}P \\
\text { Value }\end{array}$} \\
\hline & Cukup & Baik & & \\
\hline Kurang & 4 & 1 & 5 & \\
\hline Cukup. & 6 & 10 & 16 & 0,001 \\
\hline Baik & 1 & 8 & 9 & \\
\hline Total & 11 & 19 & 30 & \\
\hline
\end{tabular}

Berdasarkan tabel diatas nilai $\mathrm{p} 0,001$ $(<0,05)$ maka dapat disimpulkan terdapat perbedaan sebelum dan setelah diberikan penyuluhan.

Pelaksanaan kegiatan lain yaitu pemeriksaan. Hasilnya pada hasil pemeriksaan diperoleh data:

Tabel.3 Distribusi ibu hamil berdasarkan hasil pemeriksaan Hemoglobin

\begin{tabular}{ccc}
\hline Hasil Pemeriksaan & & \\
& Jumlah & $\%$ \\
\hline Tidak anemia & 11 & 37 \\
Anemia Ringan & 10 & 33 \\
Anemia Sedang & 9 & 30 \\
\hline Total & 30 & 100
\end{tabular}

Berdasarkan Tabel 3. Dapat diketahui 63\% ibu hamil mengalami anemia yang diklasifikasikan menjadi anemia ringan $33 \%$ dan anemia sedang $30 \%$.

Senam Hamil dilaksanakan pada pertemuan terakhir pada kegiatan senam ini diperoleh hasil:

a. Seluruh ibu hamil (100\%) mengikuti senam hamil

b. Sebagian besar ibu hamil aktif mempraktikkan sesuai dengan arahan instruktur senam.

c. Tempat kegiatan dibalai desa yang cukup luas sehingga ibu hamil dalam melakukan gerakan leluasa.

\section{PEMBAHASAN}

1. Penyuluhan tentang kebutuhan dasar ibu hamil.

Berdasarkan hasil analisis perbedaan pengetahuan diketahui bahwa terjadi peningkatan pengetahuan sebelum dan setelah penyuluhan dengan nilai $\mathrm{p} 0,001$. Penyuluhan kesehatan membawa dampak yang positif terhadap pengetahuan ibu 
hamil, hal ini juga dapat diketahui sebelum penyuluhan ada 5 ibu hamil yang memiliki pengetahuan kurang, namun setelah dilakukan penyuluhan prosentase pengetahuan kurang adalah $\mathrm{o} \%$, artinya seluruh ibu hamil mengalami peningkatan pengetahuan. Penyuluhan Kesehatan mampu meningkatkan pengetahuan, dengan adanya peningkatan pengetahuan maka diharapkan akan terjadi perubahan sikap dan perilaku. Pengetahuan juga akan semakin meningkat jika dilakukan secara berkelanjutan (Notoatmodjo, 2012).

Hasil dari pengabdian masyarakat ini yang berkaitan dengan perubahan pengetahuan sebelum dan setelah penyuluhan sejalan dengan penelitian yang telah dilakukan Indrawati, Damayanti dan Nurjanah, 2018 yang menyatakan bahwa terjadi peningkatan pengetahuan ibu hamil sebelum dan setelah dilakukan penyuluhan menggunakan media LCD dan Leaflet dengan nilai mean sebelum penyuluhan 3,00 dan setelah penyuluhan menjadi 17,90 .

Penyuluhan merubah pengetahuan dari tidak tahu menjadi tahu, karena dalam penyuluhan kesehatan terjadi suatu transfer ilmu dari bidan kepada ibu hamil. Peran bidan selama kehamilan sangat berpengaruh dalam meningkatkan kesehatan ibu hamil. Dukungan bidan diperlukan sebagai upaya ibu hamil dalam menjaga kesehatan kehamilannya, hal ini diketahui dari hasil penelitian Nursal dan Kasman (2018) menyatakan ibu hamil yang mendapatkan dukungan bidan mengalami komplikasi selama kehamilan memiliki prosentase yang kecil dibandingkan dengan ibu hamil yang kurang mendapatkan dukungan dari bidan. Hal ini berarti dalam penyampaian materi penyuluhan agar mendapatkan hasil yang diharapkan, seorang bidan harus mampu memberikan argumentasi yang dapat menarik perhatian ibu hamil agar memahami informasi yang disampaikan, sehingga diharapkan mampu merubah perilaku ibu kea rah yang lebih baik dalam menjalani kehamilannya.
2. Pemeriksaan ibu hamil meliputi Tekanan Darah, Berat Badan, Tinggi Badan, Lingkar lengan atas, Hemoglobin dan Gula darah.

Pada pengabdian masyarakat ini, pemeriksaan darah yang dilakukan adalah hemoglobin dan Glucosa blood. Hasil yang diperoleh sebesar $67 \%$ ibu hamil mengalami anemia. Anemia merupakan suatu kondisi dimana kadar Hemoglobin pada ibu hamil mengalami penurunan dari kadar normal. Pada ibu hamil kondisi anemia apabila nilai kadar HB dibawah 11 gr/dl untuk trimester 1 dan 3. Sedangkan untuk trimester 2 kurang dari 10,5 gr/dl. Kondisi penurunan kadar $\mathrm{Hb}$ secara fisiologis dialami ibu hamil karena disebabkan hemodilusi (pengenceran darah) dan puncaknya terjadi pada usia kehamila 32-34 minggu (Wiknjosastro, 2015).

Pengukuran Hemoglobin menggunakan alat digital yaitu Easy Touch GHb merupakan alat yang praktis untuk mengukur $\mathrm{Hb}$ pada ibu hamil, karena akurat, tidak menimbulkan rasa sakit, dapat dilakukan kapan saja dan dimana saja. Hasil penelitian yang dilakukan Purwanti dan Maris (2012) pemeriksaan HB dengan menggunakan $\mathrm{Hb}$ digital memiliki perbedaan 2,5 gr/dl jika dibandingkan dengan $\mathrm{Hb}$ sahli. Sehingga apabila hasil pemeriksaan pada $\mathrm{Hb}$ sahli menunjukkan kondisi tidak anemia belum tentu menujukkan hasil yang sebenarnya jika dibandingkan menggunakan Easy Touch $G H b$ yang sudah dilakukan kalibrasi.

3. Senam dan Postur tubuh bagi ibu hamil Upaya yang dapat dilakukan dalam rangka meningkatkan kebugaran dan postur tubuh yang baik bagi ibu hamil, maka pada pengabdian masyarakat ini dilaksanakan demonstrasi senam hamil dan body mekanik bagi ibu hamil. Pada kehamilan terkadang ibu mengalami keluhan dan ketidaknyamanan terutama yang terjadi pada punggung bagian bawah. Hal ini terjadi karena postur tubuh ibu hamil yang menjadi lordosis dan beban bayi dalam kandungan semakin berat, sehingga 
menyebabkan ibu sering mengeluh pegal dan nyeri punggung.

Keluhan nyeri punggung dapat diatasi dengan melakukan senam hamil. Hal ini sesuai dengan penelitian yang dilakukan Putih dan Nuraeni (2017) Nyeri punggung sebelum dilakukan senam hamil $64,7 \%$ setelah dilakukan senam hamil menjadi tidak nyeri sebesar 79,4\%. Yu (2010) menjelaskan bahwa salah satu upaya untuk menjaga kesehatan dan kebugaran pada ibu hamil dengan melakukan olahraga ringan selama kehamilan contohnya adalah senam hamil. Penurunan nyeri punggung dengan senam hamil karena gerakan dalam senam hamil mampu memperkuat otot abdomen yang berfungsi sebagai mengontrol pelvis saat menengadah. Saat ligament pada sekitar pelvis mengalami peregangan dan tidak mampu lagi menopang dengan kuat, maka akan terjadi nyeri punggung. Sehingga perlu adanya latihan sebagai upaya menjaga tonus otot abdomen dengan baik (Myles dalam Putih dan Nuraeni, 2017)

\section{KESIMPULAN}

Pelaksanaan pengabdian masyarakat dilaksanakan selama 6 bulan dan untuk pertemuan dilakukan sebanyak 4 kali. Dapat disimpulkan

1. Terjadi peningkatan pengetahuan ibu hamil tentang kebutuhan dasar pada ibu hamil sebelum dan setelah penyuluhan dengan nila $\mathrm{p} 0,001$.

2. Pemeriksaan $\mathrm{Hb}$ diperoleh $67 \%$ ibu hamil mengalami anemia.

3. $100 \%$ ibu hamil melaksanakan senam hamil.

\section{DAFTAR PUSTAKA}

Goni, A., Laoh, J \& Damanjanty. 2013. Hubungan pengetahuan dan Sikap ibu hamil dengan status gizi selama kehamilan di Puskesmas Bahu Kota manado. Ejurnal Keperawatan (e-Kp) Volume 1 Nomor 1, Agustus 2013

Indrawati, ND., Damayanti, FN., Nurjanah, S. 2018. Peningkatan pengetahuan dan sikap ibu hamil resiko tinggi dengan penyuluhan berbasis media. Jurnal Kebidanan 7(1), 69-79 DOI : 10.26714/jk.7.1.2018.69-79

Khairi S, Setyowati \& yati afiyanti. 2013.

Kegagalan memutuskan pemenuhan kebutuhan Nutrisi Selama kehamilan : studi Grounded theory pada Ibu hamil anemia. Jurnal keperawatan Indonesia Volume 16 nomor 2, Juli 2013 hl 85-92 pISSN 14104490, eISSN 2354-9203

Kuswanti, I, 2014, Asuhan Kehamilan, Yogyakarta : Pustaka Pelajar

Manuaba IBG. 2012. Ilmu Kebidanan, Penyakit Kandungan dan Keluarga Berencana. Jakarta : EGC

Notoadmodjo, S. 2012. Promosi Kesehatan dan Perilaku Kesehatan. Jakarta: Rineka Cipta

Nursal, DGA dan Kasman, R. 2018. Hubungan perilaku ibu, dukungan suami dan bidan dengan kehamilan resiko tinggi di puskesmas Pauh. Jurnal Kesehatan Masyarakat Andalas 12(2) 84-89

Purwaningrum, Y. 2017. Pengetahuan ibu hamil tentang Gizi dengan Kejadian anemia selama kehamilan. Jurnal Kesehatan. 5 (2) 21-27

Purwanti, S dan Maris, IP. 2012. Perbandingan $\mathrm{Hb}$ Ibu hamil menggunakan $\mathrm{Hb}$ Sahli dan easy Touch GHb di BPS Sulis desa Grinting Kabupaten Brebes. Jurnal Kesmasindo 5(1) 65-74

Putih, FT dan Nuraeni, A. 2017. Pengaruh Senam hamil Terhadap penurunan nyeri punggung dan peningkatan durasi waktu tidur pada ibu hamil trimester ketiga di wilayah puskesmas penawangan II Kabupaten Grobogan. Jurnal Kesehatan SSTIKES Telogorejo

Wiknjosastro, P. 2015. Ilmu Kebidanan. Jakarta: YBPP. 